\title{
Performance Analysis of Various Advanced Oxidation Processes on COD Removal from Raw Petroleum Refinery Effluent
}

\author{
Sri Martini ${ }^{1,2,+\odot} \cdot$ Sharmeen Afroze $^{2 \odot} \cdot$ Mira Setiawati $^{3 \odot}$ \\ ${ }^{1}$ Chemical Engineering Department, Muhammadiyah University of Palembang \\ ${ }^{2}$ Chemical and Petroleum Engineering Department, Curtin University \\ ${ }^{3}$ Civil Engineering Department, Muhammadiyah University of Palembang
}

(Received May 4, 2021; Revised June 11, 2021; Accepted June 21, 2021)

Objectives: This comparative study investigated various methods of advanced oxidation processes (AOPs) that were separately conducted for treating raw petroleum refinery effluent regarding chemical oxygen demand (COD) removal.

Methods : Fenton, photo-Fenton, $\mathrm{TiO}_{2}, \mathrm{ZnO}, \mathrm{TiO}_{2} / \mathrm{Ultra}$ violet (UV), and $\mathrm{ZnO} / \mathrm{UV}$ were performed individually for measuring the effect of light irradiation, treatment time, $\mathrm{pH}$, catalysts dosage, and light source on the profile of COD values.

Results and Discussion: The experimental data of this work showed that the dependency on the light exposure in heterogeneous photo-catalytic reaction using $\mathrm{TiO}_{2}$ and $\mathrm{ZnO}$ is higher than that of homogeneous photo-Fenton technique. The optimum operating conditions in heterogeneous system occurred at $100 \mathrm{~min}$ of oxidation time, $\mathrm{pH}$ 5 , and catalyst dosage $1 \mathrm{~g} / \mathrm{L}$ that resulted in $21.8,20.68,60.9$, and $55.17 \%$ of COD removal for $\mathrm{TiO}_{2}, \mathrm{ZnO}$, $\mathrm{TiO}_{2} / \mathrm{UV}$, and $\mathrm{ZnO} / \mathrm{UV}$, respectively. In contrast, both Fenton and photo-Fenton experienced their highest performance at $\mathrm{pH} 4$ by obtaining 44.2 and $59.77 \%$ of COD removal, respectively. Eventually, kinetic study indicated that COD degradation can be well expressed by second-order pattern that reached higher correlation coefficient values by 0.999 and 0.998 for $\mathrm{TiO}_{2} / \mathrm{UV}$ and $\mathrm{TiO}_{2}$, respectively.

Conclusions: Overall, it could be assumed that AOPs are reliable techniques to purify raw and complex raw industrial effluents.

Keywords: COD Removal, Petroleum Refinery Effluent, Natural Solar Light, $\mathrm{TiO}_{2}$.

\footnotetext{
Corresponding author

E-mail: srimartini79@gmail.com

Tel: +62-711-510820 Fax: +62-711-519408

(c) 2021, Korean Society of Environmental Engineers
}

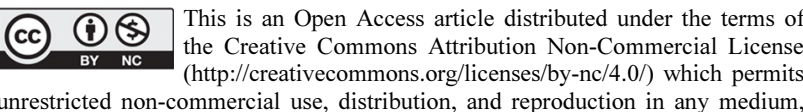
unrestricted non-commercial use, distribution, and reproduction in any medium, provided the original work is properly cited. 


\section{Introduction}

The increasing number of industrial manufacturers has directly and indirectly resulted in harmful impact on the quality of environment and living creatures. ${ }^{1,2)}$ As one of the prominent industries, petroleum refinery sector contributes significantly to the total industrial effluents containing organic and inorganic contaminants. There are some hazardous contaminants detected in this effluent such as phenol, suspended solid, heavy metals, oil, and aromatic compounds. ${ }^{2,3)}$ From this point of view, it has been a logical consequence to implement proper precaution steps to avoid environmental damage due to the presence of untreated or less treated petroleum refinery effluent (PRE) by applying particular treatments in the first stage.

To date, the availability of treatment technologies for water and effluent purification has enable related industry stakeholders and academic circle to minimize or totally eradicate targeted contaminants from industrial effluent. Literature shows that membrane filtration, adsorption, flocculation, coagulation, advanced oxidation processes (AOPs), and biological methods are available treatment options. ${ }^{2-5)}$ Among others, AOPs have been regarded promising due to its high efficiency and various possible options. ${ }^{6,7)}$ Other than that, for both homogeneous and heterogeneous processes that need light irradiation, the use of natural light source offers advantageous features including cost-effective and competitive efficiency.

AOPs have several modes such as Fenton, photo-Fenton, Fenton like, ion exchange, and various photo-catalysis types using metal oxides. There are several catalysts or metal oxides such as $\mathrm{TiO}_{2}, \mathrm{ZnO}, \mathrm{MgO}, \mathrm{ZnS}$, and $\mathrm{CdS}$ that can cooperate well with light irradiation to conduct photo-catalytic reactions. However, compared with its peers, $\mathrm{TiO}_{2}$ could be considered more reliable due to its endurance to photo corrosion, safe, and high efficiency along with working well at various wavelengths. $^{8-10)}$

Literature also shows that certain AOPs methods have satisfactory outputs for reducing COD and TOC in raw effluent containing particular recalcitrant contaminants. ${ }^{5,7,10)}$ Despite some findings related to the use of AOPs in treating synthetic wastewaters that have been reported, the application of AOPs methods on various types of raw industrial effluent and the comparative analysis of COD removal along with $\mathrm{pH}$, light irradiation, treatment time and various light sources still need to be further discussed and evaluated. The value of COD in contaminated water and industrial effluents is important to be deeply assessed as it is one of important standards representing the level of recalcitrant pollutants contained. ${ }^{11,12)}$ Therefore, the objectives of this work are; (1) to investigate and compare the efficiency of six types of AOPs comprising Fenton, photo-Fenton, $\mathrm{TiO}_{2}, \mathrm{ZnO}, \mathrm{TiO}_{2} / \mathrm{UV}$, and $\mathrm{ZnO} / \mathrm{UV}$ on COD removal using natural solar light on raw PRE (2) to specifically measure the effect of light irradiation, treatment time, solution $\mathrm{pH}, \mathrm{H}_{2} \mathrm{O}_{2}$ and catalysts dosage, and different light sources on COD removal efficiency, and (3) to analyze the kinetics of degradation.

\section{Materials and methods}

\subsection{Raw effluent sample}

The collected sample from local petroleum refinery effluent plant was taken from the outlet pond of the Dissolved Air Flotation (DAF) system before sending it to the Biological Treatment Unit (BTU). It was immediately characterized for obtaining initial characteristics. The results of characterizations on raw and treated sample can be seen in Table 1.

\subsection{Chemicals and analytical methods}

Hydrogen peroxide $\left(\mathrm{H}_{2} \mathrm{O}_{2}, 30 \% \mathrm{w} / \mathrm{v}\right)$, hydrochloric acid $(\mathrm{HCl}, 32 \%)$, ferrous sulphate hydrate $\left(\mathrm{FeSO}_{4} .7 \mathrm{H}_{2} \mathrm{O}, 99 \%\right)$, and titanium (IV) oxide $\left(\mathrm{TiO}_{2}-\mathrm{P} 25,99.7 \%\right)$ anatase from Sigma-Aldrich were used in this work. The measurement of COD concentration was conducted using HACH DRB200 reactor, DR890 colorimeter and $\mathrm{HACH}$ COD reagent vials from Rowe based on standard method 5220. TOC concentration was analyzed using a Shimadzu TOC-V CPH analyzer. Natural solar light intensity was measured by Licor Light Meter, model Li-250A.

The oil concentration $(\mathrm{mg} / \mathrm{L})$ was measured by a gravimetric method. Measured PRE sample put in a weighed separating funnel. A few drops of sulphuric acid $\left(\mathrm{H}_{2} \mathrm{SO}_{4}\right)$ solution then were added to obtain $\mathrm{pH} 2.0$ before adding $3 \mathrm{~mL}$ of $\mathrm{n}$-hexane.

Table 1. Characteristics of raw PRE used in this work.

\begin{tabular}{cc} 
Parameter & Raw PRE \\
Turbidity $(\mathrm{mg} / \mathrm{L})$ & 7.4 \\
\hline $\mathrm{COD}(\mathrm{mg} / \mathrm{L})$ & 870 \\
\hline $\mathrm{pH}$ & 9.2 \\
\hline $\mathrm{TOC}(\mathrm{mg} / \mathrm{L})$ & 135 \\
\hline $\mathrm{Cr}(\mathrm{III})(\mathrm{mg} / \mathrm{L})$ & 1.120 \\
\hline Oil and grease $(\mathrm{mg} / \mathrm{L})$ & 300 \\
\hline
\end{tabular}


The separating funnel was mechanically shaken for $2 \mathrm{~min}$ and left to form separate layers. Then $10 \mathrm{~g}$ of anhydrous sodium sulphate $\left(\mathrm{Na}_{2} \mathrm{SO}_{4}\right)$ was put on filter paper covering the weighed round bottomed flask mouth. The oil layer was further collected. Furthermore, the hexane in oil was separated using rotary evaporator. The oil sample in the round flask was dried at $103^{\circ} \mathrm{C}$ for $15 \mathrm{~min}$, it then put in the desiccator at room temperature before weighing it digitally.

Turbidity was measured using Turbidity (ISO) portable meter (Hanna instruments). The $\mathrm{pH}$ was measured using a $\mathrm{pH}$ meter glass electrode (SP-701LI 120).

The concentration of $\mathrm{Cr}(\mathrm{III})$ was determined using a Shimadzu flame model AA-7000 machine of Atomic Absorption Spectrophotometry (AAS) with standard solution and operation set by the manufacture.

The values of COD, oil and Cr(III) removal efficiencies were determined by using Eq. (1) as follows. ${ }^{27)}$

$$
\text { Removal efficiency (\%) }=\frac{C_{0}-C_{e}}{C_{0}} \times 100 \%
$$

Where $C_{0}$ and $C_{e}$ are the initial and final concentration $(\mathrm{mg} / \mathrm{L})$ of the effluent, respectively.

\subsection{Experimental set up}

All batch oxidation experimental works were carried using $250 \mathrm{~mL}$ of Pyrex glass beakers. Each beaker was equipped with a magnetic stirrer and put on a digital magnetic plate (Fig. 1). All sample solutions (100 mL each) were treated under the same operating condition related to Fenton and catalysts dosage. There was no $\mathrm{pH}$ adjustment during oxidation treatment time. The samples from batch reactor were then withdrawn at designated time using a gas tight syringe and filtrated using $0.45 \mu \mathrm{m}$ polyvinylidene fluoride membrane syringe before performing further analysis. Fenton experiment was conducted without light irradiation, while photo-Fenton was done with the help of light. In this work, natural solar light intensity was mainly used, and it is measured using light meter. Based on controlled measurement, the average value of natural solar light intensity during the experimental work was $1,550 \mu \mathrm{moles} / \mathrm{m}^{2} / \mathrm{s}$. Moreover, solar simulator and LED lamp box having light intensity of $1,000 \mathrm{~mW} / \mathrm{cm}^{2}$ and 4 lamps $\times 18 \mathrm{~W}$, respectively, were utilized as other comparative light sources.

Additionally, each experiment was conducted twice to get the average value of final calculation. It is worthy to mention

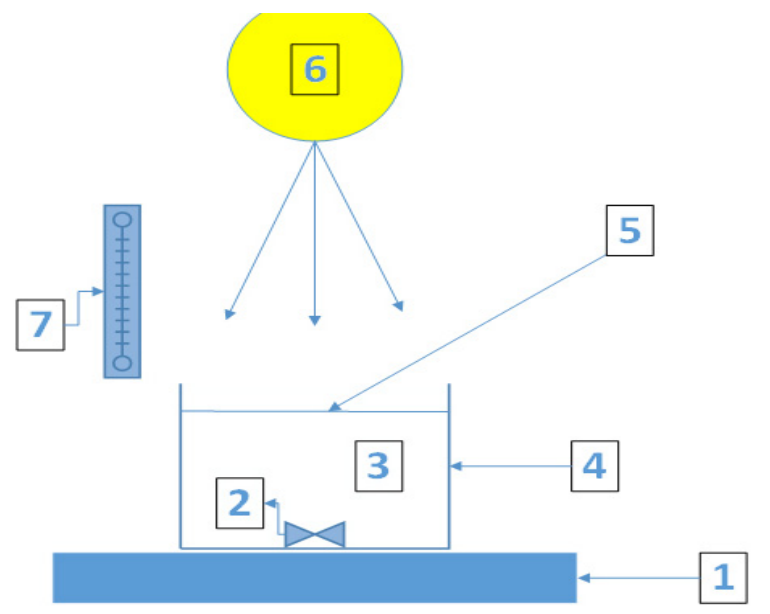

Fig. 1. Batch experiment (1. digital magnetic plate, 2. magnetic stirrer, 3. PRE sample, 4. beaker glass, 5. fenton solution/ semiconductor $\left(\mathrm{TiO}_{2}, \mathrm{ZnO}\right), 6$. light irradiation, 7. light meter).

that weather forecast became the first consideration before conducting photo-oxidation and photo-catalysis experiments which needed sunny days condition.

\section{Results and discussion}

\subsection{Effect of light exposure and treatment time}

Fig. 2 illustrates the profiles of COD removal efficiency from raw PRE regarding light exposure along with treatment time in selected AOPs methods. From the figure, it can be assumed that exposing natural solar light on the effluent sample containing $\mathrm{H}_{2} \mathrm{O}_{2}$ or semiconductor namely $\mathrm{TiO}_{2}$ or $\mathrm{ZnO}$, has resulted in a massive boost on COD removal efficiency. The discrepancy of removal efficiency values among the samples is a linear effect of the amount of hydroxyl radicals produced. This relates to the existence of those oxidants or semiconductors that are useful for mineralizing organic compounds contained in the effluent. ${ }^{13)}$ From this point of view, it is well accepted that photo-catalytic process could perform much better than dark catalytic reaction.

For homogeneous oxidation system, this study found that Fenton method was inferior to photo-Fenton which could remove more than $57 \%$ of COD from raw PRE. Despite displaying lower performance than photo-Fenton, dark Fenton could yield relatively satisfactory result when it was compared with dark catalysis reactions involving $\mathrm{TiO}_{2}$ and $\mathrm{ZnO}$. The formation of strong hydroxyl radicals supported by the existence of ferrous salt and oxidation process could be linked to this phenomenon. ${ }^{5)}$ 


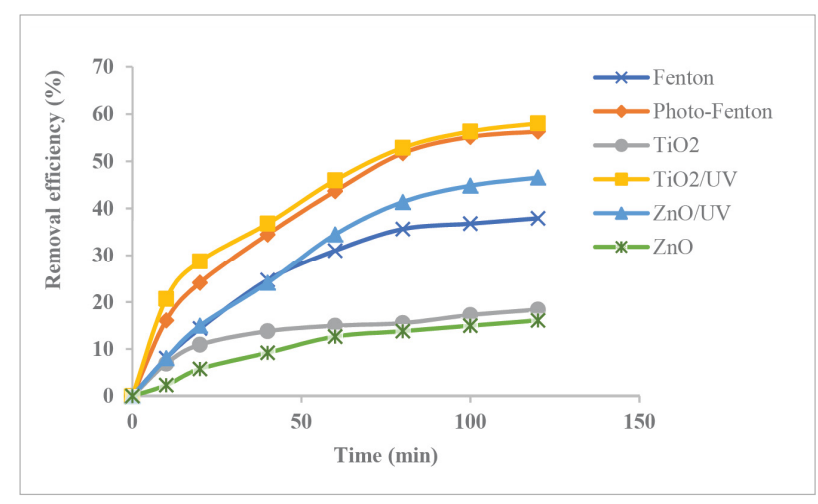

Fig. 2. The profiles of COD removal during treatment time (pH 8.5, dosage $1 \mathrm{~g} / \mathrm{L}$, natural solar light source).

On the other flip side, for heterogeneous oxidation processes, both $\mathrm{TiO}_{2} / \mathrm{UV}$ and $\mathrm{ZnO} / \mathrm{UV}$ lines visibly imply their superiority to dark $\mathrm{TiO}_{2}$ and $\mathrm{ZnO}$ lines as light involvement in hydroxyl production has lifted up COD removal more than double from $18.4 \%$ to $58 \%$ and from $16 \%$ to $46 \%$, respectively. It indicates that light exposure on heterogeneous method plays more important role in the increasing value of organic contaminants reduction. On the contrary, Fenton solution consisting of peroxide and iron compounds was less dependent on light irradiation, even though the presence of UV positively contributed to the increasing COD degradation to a better level. This can be connected to the theoretical function of solar irradiation as the main energy source to decomposing both organic and inorganic substances. ${ }^{10)}$ In other words, semiconductor like $\mathrm{TiO}_{2}$ and $\mathrm{ZnO}$ photogenerated holes boosted by UV or visible light exposure might lead to more oxidation reaction generating more. $\mathrm{OH}$ radical accountable for organic compound degradation. Fig. 2 also informs that the rate of oxidation processes with UV irradiation was inclined to getting slower increase after $80 \mathrm{~min}$. Therefore, the optimum value for irradiation time could be estimated at 100 $\min$.

In contrast, dark catalytic reactions seemed to reach their steady state conditions earlier. Both dark catalytic processes experienced stagnant lines faster. This could be caused by the absence of light exposure. ${ }^{6,14)}$

\subsection{Effect of $\mathrm{pH}$}

The value of $\mathrm{pH}$ solution is one of critical measures influencing pollutant removal even though its leverage could be different depending on the effluent characteristics and other operating conditions. ${ }^{5,15)}$ Fig. 3 represents the importance of having suitable $\mathrm{pH}$ condition during experimental work in

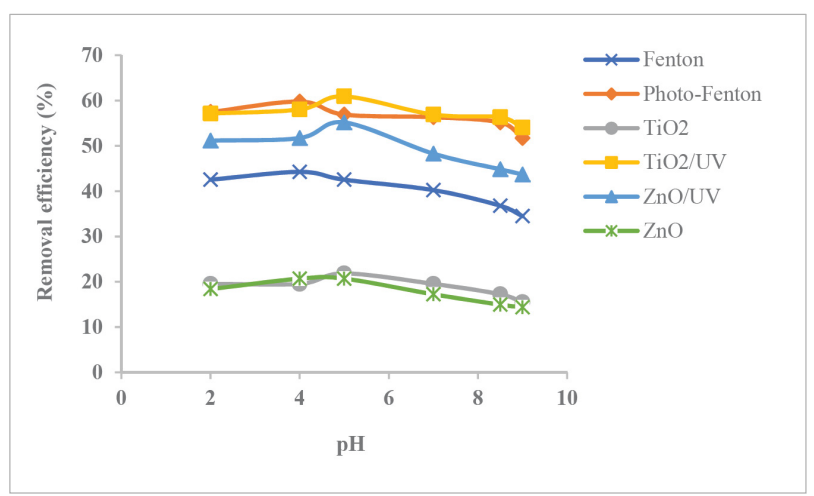

Fig. 3. The profiles of COD removal during treatment time regarding $\mathrm{pH}$ value (time $100 \mathrm{~min}$, dosage $1 \mathrm{~g} / \mathrm{L}$, natural solar light source).

order to get higher pollutant removal efficiency. This figure reflects the effect of $\mathrm{pH}$ on $\mathrm{COD}$ degradation where certain level of acidic solution could positively influence COD removal. By observing Fig. 3, homogeneous oxidation processes like Fenton and photo-Fenton were inclined to perform better at $\mathrm{pH} 4$ by reaching COD removal around $44 \%$ and $60 \%$, respectively. However, $\mathrm{TiO}_{2} / \mathrm{UV}$ catalytic process could surpass those values at $\mathrm{pH} 5$ by getting around $70 \%$ of $\mathrm{COD}$ reduction.

This trend occurred in all oxidation reaction involving semiconductors used in this study. It means that acidic condition seems to be favorable environment benefiting mineralization process of harmful organic and inorganic contaminants in raw refinery effluent. At acidic solution, there is an increasing intention of electrostatic interaction between Fenton agent or active semiconductor sites and substrate molecules influencing the encounter probability of produced hydroxyl radicals with pollutant particles. ${ }^{16)}$ Other than that, $\mathrm{pH}$ level also has an effect on the acid-base equilibrium managing the surface chemistry of metal oxides in the solution. It relates to point of zero charge of the semiconductor. The $\mathrm{TiO}_{2}$ nanoparticles, for example, has a positive charge when the $\mathrm{pH}$ is lower than its point of zero charge. In contrast, sample solution could have negative charge when the $\mathrm{pH}$ is greater than acid dissociation constant. $^{17)}$

However, it is worthy to deeply observe Fig. 3 indicating that $\mathrm{TiO}_{2} / \mathrm{UV}$ showed less different pattern between more acidic and basic $\mathrm{pH}$ level except for $\mathrm{pH} 5$ even though the downward tendency of COD removal at more neutral and basic solution occurred in nearly all of lines. In addition, at pH 2 and 4, both COD removal values were around 58\% while at neutral $\mathrm{pH} 7$ and initial $\mathrm{pH} 8.5$, the lines showed around 
$56 \%$ of COD removal before it further decreased at $\mathrm{pH} 9$.

In addition, the quality of treated effluent also became better after experiencing $\mathrm{TiO}_{2} / \mathrm{UV}$ at $\mathrm{pH} 5$ as stated in Table 1. It is clear that decreasing COD will lead to the decrease in other hazardous pollutants including heavy metal $\mathrm{Cr}$ (III) and oil and grease. This positive result may refer to the existence of $\mathrm{TiO}_{2}$ particles influencing the rate of degradation due to the adsorption of those oil grease and metal molecules on the $\mathrm{TiO}_{2}$ surface or pore. ${ }^{18,19)}$

\subsection{Effect of fenton and catalyst dosage}

Fig. 4 informs the effect of Fenton and semiconductor dosage on the profile of COD removal efficiency. While oxidant or catalysts dosage was varied, other operating parameters were kept constant including $\mathrm{pH}$, treatment time, and sample volume by $8.5,100 \mathrm{~min}$, and $100 \mathrm{~mL}$, respectively. Furthermore, based on the experimental results, oxidant dosage seemed to have significant influence on photo-catalytic reaction rate. This primary oxidant agent is responsible for highly reactive hydroxyl radical production governing targeted pollutant degradation. In specific, it is clear that increasing Fenton dosage from $0.25 \mathrm{~g} / \mathrm{L}$ to $0.5 \mathrm{~g} / \mathrm{L}$, and then to $1 \mathrm{~g} / \mathrm{L}$ have tangibly increased COD removal efficiency of photo-Fenton line from $45 \%$ to $48 \%$, and further to $55 \%$, respectively.

Nevertheless, the consistency of the increase may be different from one to the others. By observing the figure, it seems that adding more oxidant dosage by $1.25 \mathrm{~g} / \mathrm{L}$ led to slower rate of pollutant removal level into $58 \%$ before it levelled off at $1.5 \mathrm{~g} / \mathrm{L}$. This possibly has connection to the self-scavenging indication of generated hydroxyl radicals leading to saturated negative at excessive peroxide amount in the effluent. In this case, the amount of unused oxidant could put formed hydroxyl radicals to be in severe competitive environment with other organic contaminants influencing oxidation efficiency. ${ }^{20,21)}$ In other perception, those hydroxyl radicals available in the solution system might be consumed by the excess amount of $\mathrm{H}_{2} \mathrm{O}_{2}{ }^{22}$ )

Furthermore, the effect of $\mathrm{TiO}_{2}$ and $\mathrm{ZnO}$ loading on COD removal rate from PRE was also displayed in Fig. 4. The figure revealed that photo-catalysis oxidation yielded higher COD removal from around $44 \%$ to $56 \%$, and from $33 \%$ to $44 \%$, for $\mathrm{TiO}_{2} / \mathrm{UV}$ and $\mathrm{ZnO} / \mathrm{UV}$ modes, respectively, with increasing catalysts dosage from $0.25 \mathrm{~g} / \mathrm{L}$ to $1 \mathrm{~g} / \mathrm{L}$. This improvement cannot be separated from the better availability of active sites at more catalysts dosage. Hence, the

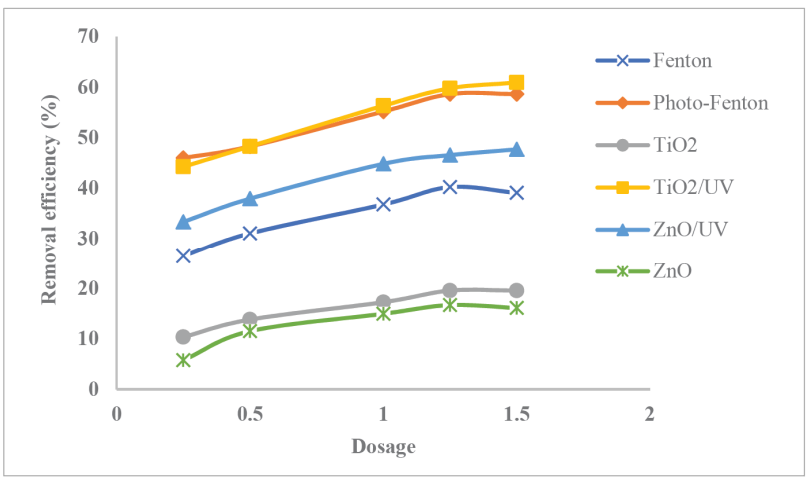

Fig. 4. The profiles of COD removal during treatment time regarding Fenton agent or catalyst dosage at $\mathrm{pH} 8.5$ and $100 \mathrm{~min}$ of reaction time, natural solar light source.

Table 2. Characteristics of treated PRW used in this work.

\begin{tabular}{cc} 
Parameter & Treated PRE $\left(\mathrm{TiO}_{2} / \mathrm{UV}\right)$ \\
Turbidity $(\mathrm{mg} / \mathrm{L})$ & 3.2 \\
\hline $\mathrm{COD}(\mathrm{mg} / \mathrm{L})$ & 340 \\
\hline $\mathrm{pH}$ & 5 \\
\hline $\mathrm{TOC}(\mathrm{mg} / \mathrm{L})$ & 48 \\
\hline $\mathrm{Cr}(\mathrm{III})(\mathrm{mg} / \mathrm{L})$ & 0.6 \\
\hline Oil and grease $(\mathrm{mg} / \mathrm{L})$ & 110 \\
\hline
\end{tabular}

electron-hole pairs formation as well as reactive hydroxyl radicals on semiconductor surface augmented. It then increased the oxidation of organic and inorganic compounds in the effluent into other intermediates. However, the increasing dosage of both $\mathrm{TiO}_{2}$ and $\mathrm{ZnO}$ up to $1.25 \mathrm{~g} / \mathrm{L}$ has caused particulates agglomeration. ${ }^{17)}$ This reduces the active sites on the catalysts surface leading to stagnant improvement of COD degradation. Additionally, more catalyst dosage may create higher turbidity level in the effluent sample detracting solar light irradiation that targeted the active surfaces of catalyst nanoparticles. In short, treated PRW has showed a better level than its raw version as stated in Table 2.

\subsection{Effect of light source}

The effect of various light sources on the profile of COD removal efficiency regarding photocatalysis and photo-Fenton processes was depicted in Fig.5. Based on the figure, it could be regarded that PRE sample having natural solar irradiation has comparable achievement to both solar simulator and LED lamp in terms of COD removal related to $\mathrm{TiO}_{2} / \mathrm{UV}$ method. However, it showed more visible discrepancy regarding homogeneous photo-Fenton process for about 5\% and 7\% higher than that of solar simulator and LED lamp. This 


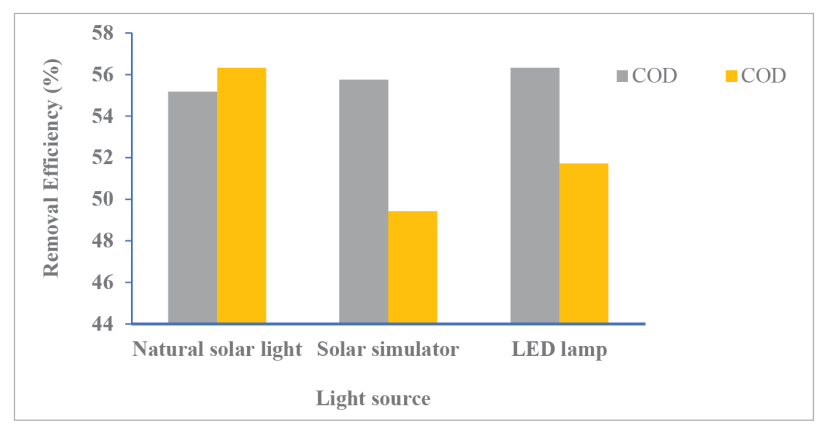

Fig. 5. Effect of light source on the profile of COD removal (Time $100 \mathrm{~min}$, dosage $1 \mathrm{~g} / \mathrm{L}, \mathrm{pH} 8.5$ ).

phenomenon could be attributed to higher accumulated energy produced at certain light intensity. In particular, light intensity will influence the capability of catalysts to adsorb more photons to generate more hydroxyl radicals. The light harvesting may comprise light absorption and charge carrier excitation expressed as the light utilization efficiency determining the total energy converted from the light, and it would be mostly examined by the structure of the band of semiconductor used in the process. ${ }^{23-25)}$

\subsection{Degradation kinetics}

It is considered that the detailed kinetic study of different individual reactions occurred during photo-chemical or photo-catalysis reactions can be complicated due to the complexity of chemical compounds as intermediates, especially in raw industrial effluent which has uncontrollable particular characteristics. Therefore, in this work, the kinetic modelling is based on the changes of targeted pollutant concentration represented as Eq. (2). ${ }^{14,26)}$

$$
\frac{d[C]}{d t}=-k[C]^{n}
$$

Where $C$ represents COD parameter, $n$ is the order of the reaction, $k$ is the reaction rate PRE coefficient, and $t$ is the reaction time. For first-order reaction, the above equation can be rewritten as Eq. (3).

$$
\frac{d[C]}{d t}=-k[C]
$$

The linearized form then is written in Eq. (4) as follows.

$$
\ln \left(C_{0}\right)-\ln (C)=-k_{t}
$$

An integration process results in Eq. (5).

$$
\ln \frac{C_{0}}{C}=k_{t}
$$

Table 3. Degradation kinetics analysis.

\begin{tabular}{ccc} 
& \multicolumn{2}{c}{ The value of $\mathrm{R}^{2}$} \\
\cline { 2 - 3 } AOPs & First order & Second order \\
Fenton & 0.860 & 0.992 \\
\hline Photo-Fenton & 0.899 & 0.974 \\
\hline $\mathrm{TiO}_{2}$ & 0.897 & 0.998 \\
\hline $\mathrm{ZnO}$ & 0.927 & 0.981 \\
\hline $\mathrm{TiO}_{2} / \mathrm{UV}$ & 0.845 & 0.999 \\
\hline $\mathrm{ZnO} / \mathrm{UV}$ & 0.935 & 0.974 \\
\hline
\end{tabular}

The second order model can be expressed as Eq. (6).

$$
\frac{t}{q_{t}}=\frac{1}{K_{2} q_{e}^{2}}+\frac{1}{q_{e}} t
$$

The value of $k_{2}\left(\mathrm{~g} \mathrm{mg}^{-1} \mathrm{~min}^{-1}\right)$ is defined as the rate constant of the second order model. In order to calculate $k_{2}$ constant and adsorption capacity in equilibrium, $t / q_{\mathrm{t}}$ and $t$ graphs were plotted. Eventually, least square regression was used to calculate the values of $\mathrm{k}$ and correlation coefficient, $\mathrm{R}^{2}$, and the results were tabulated in Table 3 .

Based on the table, it can be assumed accordingly that second order equation can fully expressed those oxidation reactions due to obtaining higher $\mathrm{R}^{2}$ values. The higher value of $\mathrm{R}^{2}$ for second order reaction refers to kinetic mechanism that is influenced by the oxidation or adsorption capacity. ${ }^{14,27)}$

\subsection{Mechanism of $\mathrm{TiO}_{2} / \mathrm{UV}$ photocatalytic degradation}

The mechanism of $\mathrm{TiO}_{2} / \mathrm{UV}$ is needed to describe the photocatalytic degradation of organic compounds. When $\mathrm{TiO}_{2}$ nanoparticles are irradiated, photogenerated holes then are produced, Eq. (7). They can continuously react with each other as shown in Eqs. (8), (9), and (10) followed by further hydroxyl radicals formation as stated in Eqs. (11) and (12). Eventually, it then starts oxidation reaction with $\mathrm{OH}^{-}$or $\mathrm{H}_{2} \mathrm{O}$ generating $\mathrm{OH}^{\prime}$ that can be expressed in Eqs. (13) and (14). When the oxygen amount is limited, the rapid recombination of photo produced electrons and holes in $\mathrm{TiO}_{2}$ can lower the efficiency of the photocatalytic reactions. Overall, the major reactions for the mechanism of $\mathrm{TiO}_{2} \mathrm{UV}$ photocatalytic oxidation can be expressed as follows ${ }^{10,28)}$ :

$$
\begin{aligned}
& \mathrm{TiO}_{2}+\mathrm{hv} \rightarrow \mathrm{TiO}_{2}\left(\mathrm{e}_{\mathrm{cb}}{ }^{-}+\mathrm{h}_{\mathrm{vb}}{ }^{+}\right) \\
& \mathrm{TiO}_{2}\left(\mathrm{~h}_{\mathrm{vb}}{ }^{+}\right)+\mathrm{H}_{2} \mathrm{O} \rightarrow \mathrm{TiO}_{2}+\mathrm{H}^{+}+\mathrm{OH}^{-} \\
& \mathrm{TiO}_{2}\left(\mathrm{~h}_{\mathrm{VB}}{ }^{+}\right)+\mathrm{OH} \rightarrow \mathrm{TiO}_{2}+\mathrm{OH}
\end{aligned}
$$




$$
\begin{aligned}
& \mathrm{TiO}_{2}\left(\mathrm{e}_{\mathrm{CB}}^{-}\right)+\mathrm{O}_{2} \rightarrow \mathrm{TiO}_{2}+\mathrm{O}_{2}^{-} \\
& \mathrm{O}_{2}^{-}+\mathrm{H}^{+} \rightarrow \mathrm{HO}_{2} \\
& \mathrm{HO}_{2}+\mathrm{HO}_{2} \rightarrow \mathrm{H}_{2} \mathrm{O}_{2}+\mathrm{O}_{2} \\
& \mathrm{TiO}_{2}\left(\mathrm{e}_{\mathrm{cb}}^{-}\right)+\mathrm{H}_{2} \mathrm{O}_{2} \rightarrow \mathrm{OH}^{-}+\mathrm{OH}^{-} \\
& \mathrm{H}_{2} \mathrm{O}_{2}+\mathrm{O}_{2}^{--} \rightarrow \mathrm{OH}^{-}+\mathrm{OH}^{-}+\mathrm{O}_{2}
\end{aligned}
$$

General mechanism of $\mathrm{TiO}_{2}$ in photocatalytic degradation can also be represented in Eqs. (15), (16), and (17) as follows.

Organic compound $+\mathrm{HO} \rightarrow$ Degradation products

Organic compound $+\mathrm{TiO}_{2}\left(\mathrm{~h}_{\mathrm{vb}}{ }^{+}\right) \rightarrow$ Oxidation product

Organic compound $+\mathrm{TiO}_{2}\left(\mathrm{e}_{\mathrm{cb}}{ }^{-}\right) \rightarrow$ Reduction product

Furthermore, the mechanism of generating the hydroxyl radicals in photo Fenton can be generalized as expressed in Eqs. (18) and (19).

$$
\begin{aligned}
& \mathrm{Fe}^{2+}+\mathrm{H}_{2} \mathrm{O}_{2} \rightarrow \mathrm{Fe}^{3+}+\mathrm{HO}^{-}+\mathrm{HO} \\
& \mathrm{Fe}+\mathrm{H}_{2} \mathrm{O}+h v \rightarrow \mathrm{Fe}^{2+}+\mathrm{HO}+\mathrm{H}^{+}
\end{aligned}
$$

Since the hydroxyl radicals can react with organic matters, it will experience further oxidation process as depicted in Eq. (20):

$$
\mathrm{HO}+\mathrm{RH} \stackrel{\text { chainpropagation }}{\longrightarrow} \mathrm{CO}_{2}+\mathrm{H}_{2} \mathrm{O}
$$

\section{Conclusions}

This comparative study separately applied selected types of advanced oxidation processes for purifying raw petroleum refinery effluent with and without natural solar light. Fenton, photo-Fenton, $\mathrm{TiO}_{2}, \mathrm{ZnO}, \mathrm{TiO}_{2} / \mathrm{UV}$, and $\mathrm{ZnO} / \mathrm{UV}$ were conducted under the same operating conditions. The experimental work strongly indicated that the existence of light irradiation in both homogeneous and heterogeneous reactions is significantly important to boost COD removal efficiency, especially in photo-catalytic reaction using semiconductor where light exposure could increase catalyst performance more than double. In term of $\mathrm{pH}$ assessment, photo-catalytic process involving $\mathrm{TiO}_{2}$ or $\mathrm{ZnO}$ tended to be more attractive at $\mathrm{pH} 4$, while oxidation reaction performed better at $\mathrm{pH}$ 5. Interestingly, $\mathrm{TiO}_{2} / \mathrm{UV}$ experienced relatively similar performance on both acidic and near neutral $\mathrm{pH}$ condition. Fenton and catalysts dosage seemed to be more favorable at $1 \mathrm{~g} / \mathrm{L}$ as their best point as higher amount of both Fenton and semiconductor nanoparticles would lead to less improvement, or even lower COD removal efficiency. The use of natural solar light can give relatively comparable output with the light of solar simulator and LED lamps related to the decrease in COD values. Overall, the analysis of kinetic mechanism supported by the experimental data showed that second-order equation expressed its conformity to oxidation reactions much better than first- order formula by reaching the highest $\mathrm{R}^{2}$ values of 0.999 and 0.998 for $\mathrm{TiO}_{2} / \mathrm{UV}$ and $\mathrm{TiO}_{2}$, respectively. Overall, the possible future research might be focused on the usage of these various methods for reducing certain recalcitrant pollutants by implementing specific ration of combined heterogeneous and homogeneous oxidation processes as well as their degradation kinetics development.

\section{Acknowledgement}

The authors thank Muhammadiyah University of Palembang and Curtin University for support given during finalizing this work.

\section{Abbreviations}

COD : Chemical oxygen demand (mg/L)

TOC : Total organic carbon $(\mathrm{mg} / \mathrm{L})$

\section{Nomenclature}

$t \quad:$ Treatment time $(\mathrm{mg} / \mathrm{L})$

$C$ : Concentration at $\mathrm{t}(\mathrm{mg} / \mathrm{L})$

$C_{o}$ : Initial concentration $(\mathrm{mg} / \mathrm{L})$

$k_{1}$ : Rate constant of the first order model $\left(\mathrm{min}^{-1}\right)$

$k_{2}$ : Rate constant of the second order model $\left(\mathrm{g} \mathrm{mg}^{-1} \mathrm{~min}^{-1}\right)$

\section{References}

1. N. U. Barambu, M. R. Bilad, M. A. Bustam, K. A. Kurnia, M. H. D. Othman, N. A. H. M. Nordin, Development of membrane material for oily wastewater treatment: a review, Ain Shams Eng. J., 12(2), 1361-1374(2021).

2. S. Martini, S. Afroze, K. A. Roni, Modified eucalyptus bark as a sorbent for simultaneous removal of COD, oil, and $\mathrm{Cr}$ (III) from industrial wastewater, Alexandria Eng. J., 59(3), 1637-1648 (2020).

3. B. Singh, P. Kumar, Pre-treatment of petroleum refinery 
wastewater by coagulation and flocculation using mixed coagulant: optimization of process parameters using response surface methodology (RSM), J. Water Proc. Eng., 36, 101317 (2020).

4. S. Huang, R. H. A. Ras, X. Tian, Antifouling membranes for oily wastewater treatment: interplay between wetting and membrane fouling, Curr. Opin. Coll. Interface Sci., 36, 90-109(2018).

5. S. N. Rao, S. Shrivastava, Treatment of complex recalcitrant wastewater using Fenton process, in Proceedings of the International Conference on Advanced Functional Materials, Physical and Biological Sciences, Stockholm, pp. 1161-1165 (2020).

6. H. Demir-Duz, O. Ayyildiz, A. S. Aktürk, M. G. Álvarez, S. Contreras, Approaching zero discharge concept in refineries by solar - assisted photo-Fenton and photo-catalysis processes, Appl. Catal B: Environ., 248, 341-348(2019).

7. Y. Guo, Q., Xue, H. Zhang, N. Wang, S. Chang, H. Wang, H. Pang, H. Chen, Treatment of real benzene dye intermediates wastewater by the Fenton method: characteristics and multi-response optimization, RSC Adv., 8(1), 80-90(2018).

8. D. A. D. A. Aljuboury, F. Shaik, Assessment of $\mathrm{TiO}_{2} / \mathrm{ZnO} / \mathrm{H}_{2} \mathrm{O}_{2}$ Photocatalyst to treat wastewater from oil refinery within visible light circumstances, South African J. Chem. Eng. 35, 69-77(2021).

9. S. Martini, H. M. Ang, Hybrid $\mathrm{TiO}_{2} / \mathrm{UV} / \mathrm{PVDF}$ ultrafiltration membrane for raw canola oil wastewater treatment, Desalin. Water Treat., 148, 51-59(2019).

10. M. R. Al-Mamun, S. Kader, M. S. Islam, M. Z. H. Khan, Photocatalytic activity improvement and application of UV-TiO 2 photocatalysis in textile wastewater treatment: a review, J. Environ. Chem. Eng., 7(5), 103248(2019).

11. Z. Zhou, T. Yu, H. Dong, L. Huang, R. K. Chu, N. Tolic, X. Wang, Q.. Zeng, Chemical oxygen demand (COD) removal from bio-treated coking wastewater by hydroxyl radicals produced from a reduced clay mineral, Appl. Clay Sci., 180, 105199(2019).

12. Z. Pan, J. Zhou, Z. Lin, Y. Wang, P. Zhao, J. Zhou, S. Liu, $X$. He, Effects of COD/TN ratio on nitrogen removal efficiency, microbial community for high saline wastewater treatment based on heterotrophic nitrification-aerobic denitrification process, Biores. Technol., 301, 122726(2020).

13. M. Antonopoulou, C. Kosma, T. Albanis, I. Konstantinou, An overview of homogeneous and heterogeneous photocatalysis applications for the removal of pharmaceutical compounds from real or synthetic hospital wastewaters under lab or pilot scale, Sci. Total. Environ., 765, 144163(2021).

14. M. Bayrakdar, S. Atalay, G. Ersöz, Efficient treatment for textile wastewater through sequential photo Fenton-like oxidation and adsorption processes for reuse in irrigation, Ceram. Int., 47(7), 9679-9690(2021).

15. J. J. Rueda-Marquez, I. Levchuk, P. F. Ibañez, M. Sillanpää, Critical review on application of photocatalysis for toxicity reduction of real wastewaters, J. Clean Prod. 258, 120694 (2020).
16. E. S. Elmolla, M. Chaudhuri, Photocatalytic degradation of amoxicillin, ampicillin and cloxacillin antibiotics in aqueous solution using $\mathrm{UV} / \mathrm{TiO}_{2}$ and $\mathrm{UV} / \mathrm{H}_{2} \mathrm{O}_{2} / \mathrm{TiO}_{2}$ photocatalysis, Desalin., 252(1-3), 46-52(2010).

17. M. G. Alalm, A. Tawfik, S. Ookawara, Comparison of solar $\mathrm{TiO}_{2}$ photocatalysis and solar photo-Fenton for treatment of pesticides industry wastewater: operational conditions, kinetics, and costs, J. Water Process Eng., 8, 55-63(2015).

18. Z. H. Diao, X. R. Xu, D. Jiang, J. J. Liu, L. J. Kong, G. Li, L. Z. Zuo, Q. H. Wu, Simultaneous photocatalytic Cr(VI) reduction and ciprofloxacin oxidation over $\mathrm{TiO}_{2} / \mathrm{Fe}^{0}$ composite under aerobic conditions: performance, durability, pathway and mechanism, Chem. Eng. J., 315, 167-176(2017).

19. Y. Mokhbi, M. Korichi, Z. Akchiche, Combined photocatalytic and Fenton oxidation for oily wastewater treatment, Appl. Water Sci., 35, 1-9(2019).

20. E. Domingues, N. Assunção, J. Gomes, D. V. Lopes, J. R. Frade, M. J. Quina, R. M. Quinta-Ferreira, R. C. Martins, Catalytic efficiency of red mud for the degradation of olive mill wastewater through heterogeneous Fenton's process, Water, 11(6), 1183(2019).

21. E. Domingues, E. Fernandes, J. Gomes, R. C. Martins, Swine wastewater treatment by Fenton's process and integrated methodologies involving coagulation and biofiltration, J. Clean Prod., 293, 126105(2021).

22. I. Nitoi, T. Oncescu, P. Oancea, Mechanism and kinetic study for the degradation of lindane by photo-Fenton process, J. Ind. Eng. Chem., 19(1), 305-309(2013).

23. X. Wang, F. Wang, Y. Sang, H. Liu, Full spectrum solar light activated photocatalysts for light-chemical energy conversion, Adv. Energ. Mater., 7(23), 1700473(2017).

24. S. Kalikeri, N. Kamath, D. J. Gadgil, V. S. Kodialbail, Visible light-induced photocatalytic degradation of Reactive Blue-19 over highly efficient polyaniline- $\mathrm{TiO}_{2}$ nanocomposite: a comparative study with solar and UV photocatalysis, Environ. Sci. Pollut. Res., 25, 3731-3744(2018).

25. M. Tanveer, G. T. Guyer, G. Abbas, Photocatalytic degradation of ibuprofen in water using $\mathrm{TiO}_{2}$ and $\mathrm{ZnO}$ under artificial UV and solar irradiation, Water Environ. Res., 91(9), 822-829(2019).

26. L. M. Nieto, G. Hodaifa, S. Rodríguez, J. A. Giménez, J. Ochando, Degradation of organic matter in olive-oil mill wastewater through homogeneous Fenton-like reaction, Chem. Eng. J., 173(2), 503-510(2011).

27. Y. S. Ho, A. E. Ofomaja, Pseudo-second-order model for lead ion sorption from aqueous solutions onto palm kernel fiber, J. Hazard. Mater., 129(1-3), 137-142(2006).

28. S. Bagwasi, B. Tian, J. Zhang, M. Nasir, Synthesis, characterization and application of bismuth and boron Co-doped $\mathrm{TiO}_{2}$ : a visible light active photocatalyst, Chem. Eng. J., 217, 108-118(2013). 


\section{Declaration of Competing Interest}

The authors declare that they have no known competing financial interests or personal relationships that could have appeared to influence the work reported in this paper.

\section{Authors and Contribution Statement}

\section{Sri Martini}

Chemical Engineering Department, Muhammadiyah University of Palembang, Chemical and Petroleum Engineering Department, Curtin University, Assistant Professor, ORCiD 두 0000-0001-63727491: Conceptualization, Data curation, Data analysis, Methodology, Visualization, Writing - original draft.

\section{Sharmeen Afroze}

Chemical and Petroleum Engineering Department, Curtin University, Ph.D., ORCiD (시 0000-0003-1939-2561: Data analysis, Methodology, Writing-editing.

\section{Mira Setiawati}

Civil Engineering Department, Muhammadiyah University of Palembang, Assistant Professor, ORCiD 다 0000-0001-6873-6418: Data analysis, Writing - review and editing. 